\title{
A global evaluation of fronts and precipitation in the ACCESS model
}

\author{
J.L. Catto, C. Jakob and N. Nicholls \\ Monash University
}

(Manuscript received July 2012; revised December 2012)

\begin{abstract}
How global precipitation will change in the future is of great socio-economic importance. It is therefore vital that climate models are able to adequately simulate the characteristics of precipitation and the individual precipitation events. Fronts play an important role in providing precipitation and they can be associated with heavy rain and flooding.

In this paper the ACCESS1.3 atmosphere model is evaluated in terms of frontal and non-frontal precipitation. An objective front identification method is applied to data from reanalysis and the model. The fronts are then linked to daily precipitation from observational estimates and the model. The proportion of precipitation associated with fronts and the average intensity of precipitation associated with fronts are then calculated and compared.

The frequency of fronts and the proportion of precipitation associated with fronts are well captured by the model. The intensity of precipitation when a front is present is underestimated by the model in most regions, consistent with many previous studies. Decomposing the total precipitation error into components associated with the frequency and intensity of both frontal and non-frontal precipitation shows that the non-frontal precipitation errors contribute the most to the total error, and that there are compensating errors in the model. This regime- and process-based method of model evaluation provides a useful tool to gain deeper understanding into the sources of precipitation errors in climate models.
\end{abstract}

\section{Introduction}

The global distribution of precipitation and its associated variability is of huge socio-economic consequence. It is therefore important for global climate models to be able to accurately simulate this distribution so that future projections of changes in precipitation distribution can be trusted. Not only must climate models represent the largescale mean precipitation climatology, it is also important that the individual precipitation events are simulated and for the correct reasons.

Recent studies have highlighted the need to evaluate precipitation from climate models not just on monthly timescales such as in Schaller et al. (2011), but also on daily timescales. The daily precipitation allows characteristics such as frequency and intensity of precipitation to be evaluated (e.g. Sun et al. 2006; Dai 2006; Brown et al. 2010). Sun et al. (2006) used daily precipitation from 18 coupled climate models to evaluate characteristics, including the

Corresponding author address: Jennifer Catto, email jennifer.catto@ monash.edu number of days that contribute to 67 per cent of the total annual rainfall, against various observational estimates. They found in the models they looked at that over land there was generally an overestimate in the frequency of occurrence of light rain (less than $10 \mathrm{~mm} /$ day) and an underestimate in the intensity of heavy rainfall (more than $10 \mathrm{~mm} /$ day), leading to a greater number of days contributing 67 per cent of the total annual precipitation. Brown et al. (2010) also separated the precipitation characteristics into frequency and intensity to evaluate a climate model for the Australian region, finding similar results to those of Sun et al. (2006). The use of selforganising maps in the study of Brown et al. (2010) allowed the contribution of precipitation from different synoptic regimes to be evaluated in the climate model. Since the model was able to represent the synoptic regimes quite well, the errors in precipitation were found to be due to problems in representing the different characteristics of the precipitation within the different regimes. This type of regime-oriented analysis has also been used to gain more understanding into trends in precipitation in Darwin (Catto et al. 2012b) by separating the trend into components from changes in the frequency of occurrence of the regimes and 
changes in the intensity of precipitation associated with each regime.

Over the mid-latitude storm track regions, Catto et al. (2012a) found up to 90 per cent of annual precipitation was associated with atmospheric fronts. These frontal precipitation events can cause severe flooding in the regions over which they pass (Mills et al. 1995, Pitt 2008, Lavers et al. 2011). Pfahl and Wernli (2012) showed that in these same regions, up to 80 per cent of precipitation extremes (based on the 99th percentile of precipitation) are associated with extratropical cyclones. An important question is whether climate models can capture these important aspects of the climate.

How precipitation, and particularly the extremes of precipitation, will change in the future is of great concern. In order to be able to provide useful information regarding flooding from frontal rain events in the future, climate models must be able to simulate not only the dynamical aspects of extratropical cyclones (Catto et al. 2010), but also the precipitation associated with their embedded fronts. The studies of Champion et al. (2011) and Bengtsson et al. (2009) found that the intensity of precipitation along the tracks of extratropical cyclones increased in 21st century simulations using the ECHAM5 model. A similar result was found in the CSIRO climate models by Watterson (2006).

Since atmospheric fronts are so important for the day-today variability of weather, particularly in the mid-latitudes, a number of recent studies have taken advantage of the availability of global gridded reanalysis datasets to create climatologies of objectively identified atmospheric fronts (Berry et al. 2011; Simmonds et al. 2012). The study of Catto et al. (2012a) combined the front identification methodology of Berry et al. (2011) with the daily precipitation from the Global Precipitation Climatology Project (GPCP) to quantify the global proportion of precipitation that comes from fronts as well as the average precipitation when a front is present.

The aim of the present study is to evaluate whether a state-of-the-art climate model can simulate the precipitation associated with fronts. The method of Catto et al. (2012a) is applied to the output from the atmosphere model of the Australian Community Climate and Earth System Simulator version 1.3 (ACCESS1.3; $\mathrm{Bi}$ et al. 2013) to evaluate the precipitation associated with fronts within the model. This process-oriented method of analysis allows the physical processes producing precipitation in the climate model to be evaluated, rather than just whether or not the model can reproduce the large spatial and temporal scale mean. The precipitation biases in the model can then be separated into components related to errors in the frequency of rainfall events with and without fronts, and errors in the intensity of precipitation associated with each of these two cases using a decomposition similar to that used in Catto et al. (2012b).

A description of the observationally constrained data against which the model will be evaluated, the model itself, and the method of analysis are given in the following section. The evaluation of the model in terms of the global frontal distribution, the proportion of precipitation associated with fronts, and the average daily precipitation from fronts is detailed in the results section along with the error decomposition analysis. The final section provides a discussion and some conclusions.

\section{Data and methodology}

\section{Reanalysis data}

The European Centre for Medium-Range Weather Forecasting (ECMWF) reanalysis dataset, ERA-Interim (Dee et al. 2006) has been used as an observationally constrained dataset against which to evaluate the climate model. The front identification methodology has been applied to the sixhourly fields at $850 \mathrm{hPa}$ for the years 1997 to 2008 to give gridded front information on a $2.5^{\circ}$ grid.

The precipitation information is gained from the Global Precipitation Climatology Project (GPCP) daily precipitation dataset (1DD; Huffman et al. 2001) which combines information from satellite, rain gauge and sounding data. The daily precipitation estimates are scaled so that the monthly totals are the same as the GPCP monthly data (Adler et al. 2003). Monthly and daily precipitation estimates from GPCP have been widely evaluated against gauge data (e.g. Bolvin et al. 2009; McPhee and Margulis 2005; Nicholson et al. 2003). The precipitation data have been interpolated to the same $2.5^{\circ}$ grid as the front data in order to facilitate the linking of the two datasets as in Catto et al. (2012a).

\section{Model}

The model used in this study is the atmosphere component of the ACCESS1.3 (Bi et al. 2013). The coupled version of this model has recently been submitted for the Fifth Coupled Model Intercomparison Project (CMIP5). The atmosphere component of the model is very similar to the UK Met Office model, MetOffice GA1.0 global atmosphere model (Hewitt et al. 2011), with a resolution of N96 (approximately $150 \mathrm{~km}$ ) in the horizontal and 38 levels in the vertical and a new prognostic cloud parameterisation (PC2; Wilson et al. 2008). An important difference between ACCESS1.3 and the model from the UK Met Office is that ACCESS1.3 uses a land surface scheme developed in Australia, CABLE (Kowalczyk et al. 2006). Here the atmosphere has been forced using observed sea surface temperatures (SSTs) for the years 1978-2007.

\section{Front identification and link to precipitation}

The front identification method of Berry et al. (2011), as used in Catto et al. (2012a), has been applied to both the reanalysis and the model data. This method used the thermal front parameter of Hewson (1998) to identify locations of frontal points at the maximum gradient of wet bulb potential temperature in the direction of the moist isentropes. The points are then linked into contiguous fronts, and separated into cold, warm and quasi-stationary fronts depending on the magnitude and direction of front speed. 
The fronts are then combined with the precipitation data as described in Catto et al. (2012a). Daily accumulated precipitation is defined as being attributed to a front if a front exists in a $5^{\circ}$ box surrounding the grid box within which the precipitation is located. The use of the $5^{\circ}$ box and the sensitivity of the method to other search regions are discussed in Catto et al. (2012a). If there is more than one type of front located in the search area within the 24-hour period, the precipitation allocated to each type of front is weighted according to the number of times or points at which that type of front occurs.

The front identification and precipitation methodology has been applied to the model in exactly the same way as the observationally constrained data. The six-hourly fronts are linked to the daily precipitation from the model, and the data have been interpolated onto the same $2.5^{\circ}$ grid. Only the regions between $60^{\circ} \mathrm{N}$ and $60^{\circ} \mathrm{S}$ have been considered as in Catto et al. (2012a). This is due to the convergence of the meridians polewards of these latitudes resulting in the frontal search area becoming smaller and smaller. In the southern hemisphere, polewards of $60^{\circ} \mathrm{S}$, mainly spurious fronts are identified at the boundary of the high orography of Antarctica, and in the northern hemisphere there are small front frequencies north of $60^{\circ} \mathrm{N}$ (Berry et al. 2011).

\section{Results}

Here, the climatology of precipitation and mean sea level pressure (MSLP) - the front frequency and various measures of precipitation associated with fronts from the model-are evaluated against observationally constrained estimates. Although the model simulation is 30 years long, there are not similarly long time series of observed daily precipitation suitable for this analysis. An investigation has been carried out into differences between the results from the 30-year simulation and the results from 12 years of simulation (only 12 years of observed data are available here). This comparison revealed that the differences between the short and long periods of model simulation are much smaller than between the model and the observations. For this reason, the results from the full 30 years of model simulation are shown in the following sections.

\section{Model climatology}

Before going into detail about fronts and precipitation in the model, it is important to check how well the model represents the climatology of precipitation and the atmospheric circulation. Figure 1 shows the annual mean precipitation from GPCP, the difference between the model and GPCP, the annual average mean sea level pressure (MSLP) from ERAInterim, and the difference between the model and ERA-

Fig. 1. Annual mean climatology of (a) precipitation from GPCP and (b) difference between annual mean climatology of precipitation ACCESS1.3 and GPCP (mm/day). Annual mean climatology of mean sea level pressure for (c) ERA-Interim and (d) difference between ACCESS1.3 and ERA-Interim (hPa).

a) GPCP Precipitation

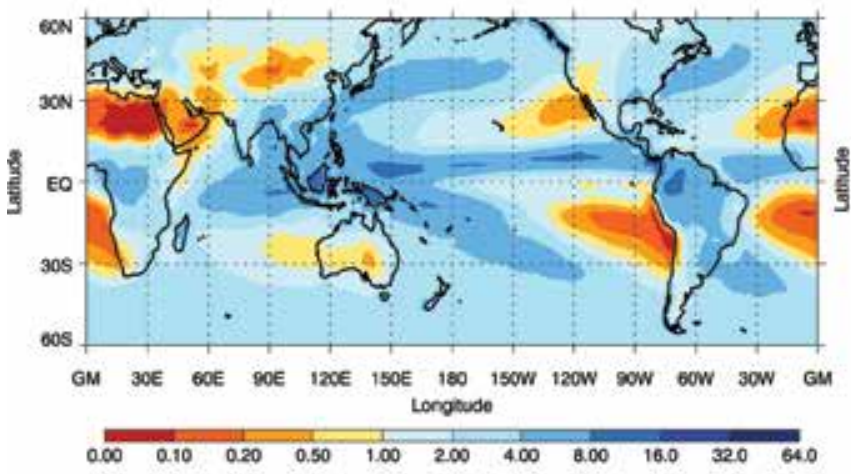

c) ERA-Interim MSLP

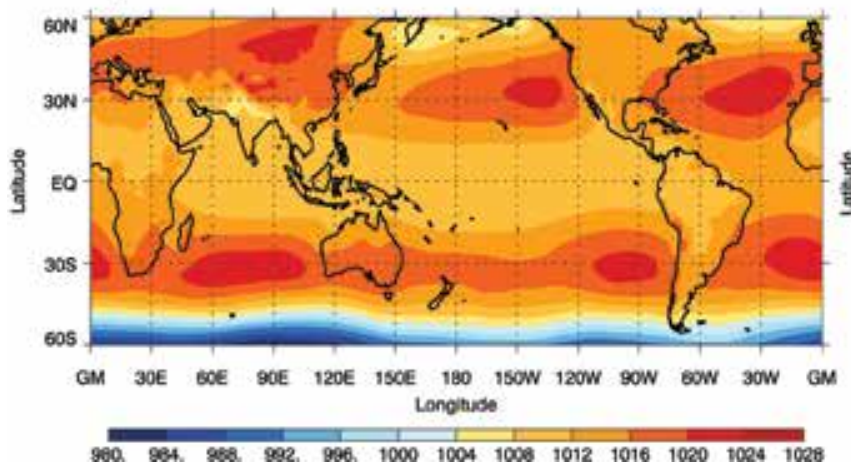

b) ACCESS1.3 - GPCP Precipitation

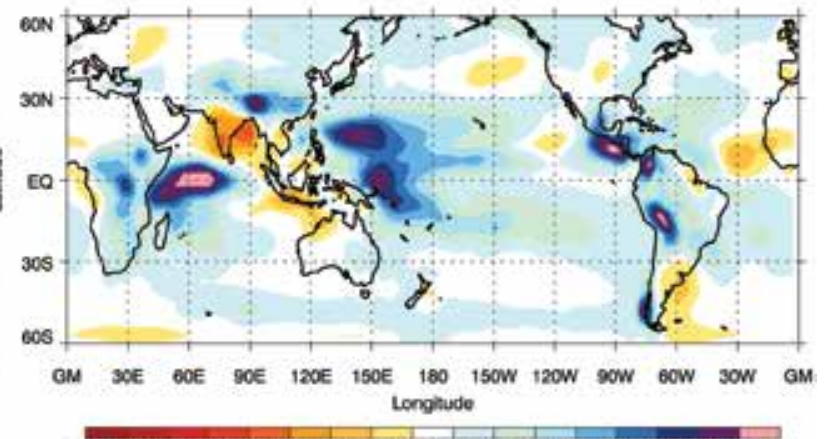

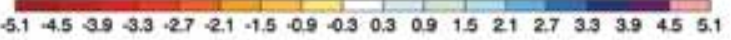
d) ACCESS1.3 - ERA-Interim MSLP

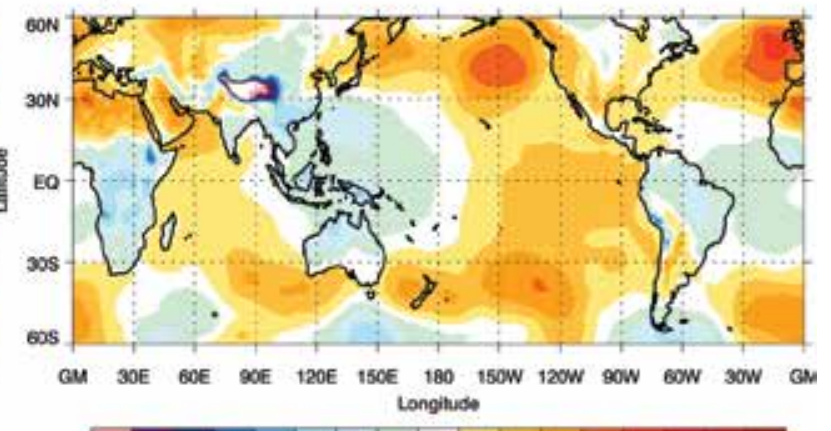

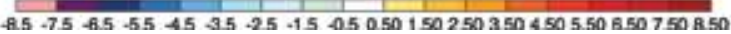


Fig. 2. Annual mean front frequency of $(a, b)$ all fronts, $(c, d)$ cold fronts, $(e, f)$ warm fronts and $(g, h)$ quasi-stationary fronts, from $(a, c, e, g)$ ERA-Interim, and (b, d, f, h) ACCESS1.3. Units are percentage time at which an objectively identified front was located within each grid box. Polewards of $\pm 60^{\circ}$ has been cut off due to problems with the convergence of the meridians.

a) Front frequency all fronts ERA-Interim

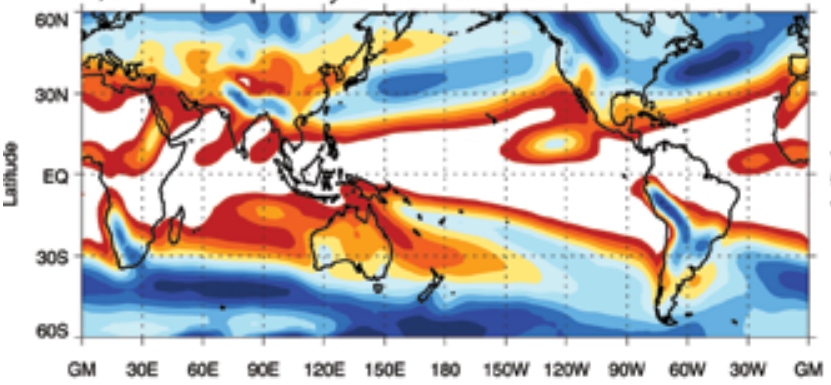

GM $30 E$ GOE SOE 120E $150 E$ 180 15OW 120W $90 \mathrm{~W}$ GOW $30 \mathrm{~W}$ GN Longlude

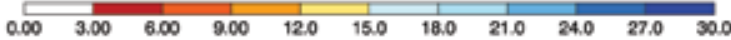

c) Cold front frequency ERA-Interim

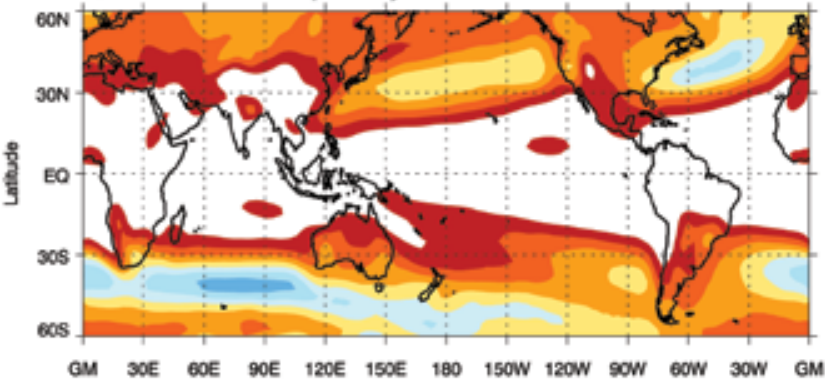

GM 3OE GOE g0E 120E $150 \mathrm{E}$ 180 150W 120W SOW GOW 30W GM Longhtude

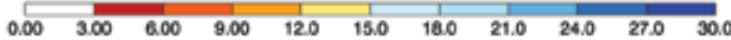

e) Warm front frequency ERA-Interim
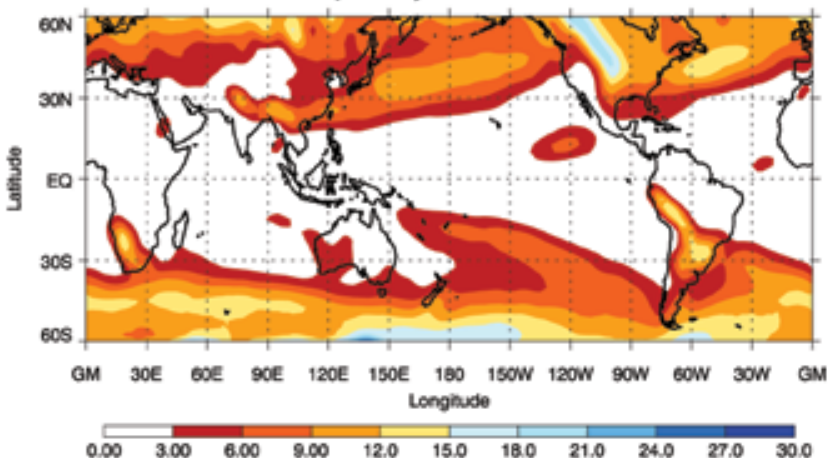

g)Quasi-stationary front frequency ERA-Interim

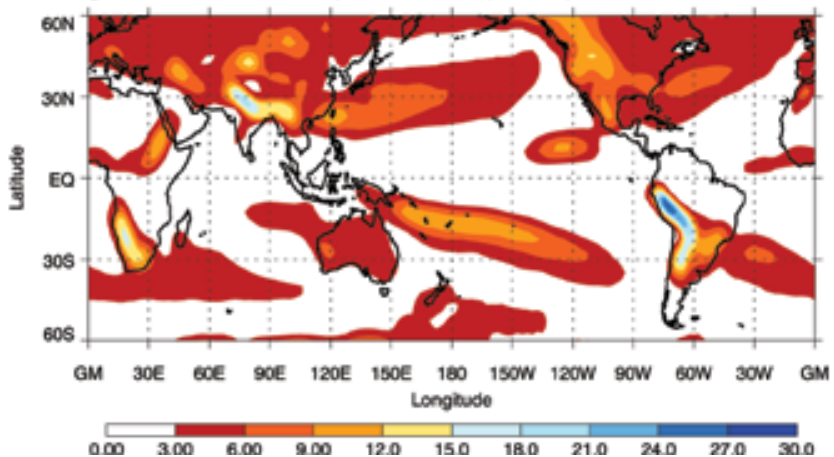

b) ACCESS1.3 - ERA-Interim front frequency

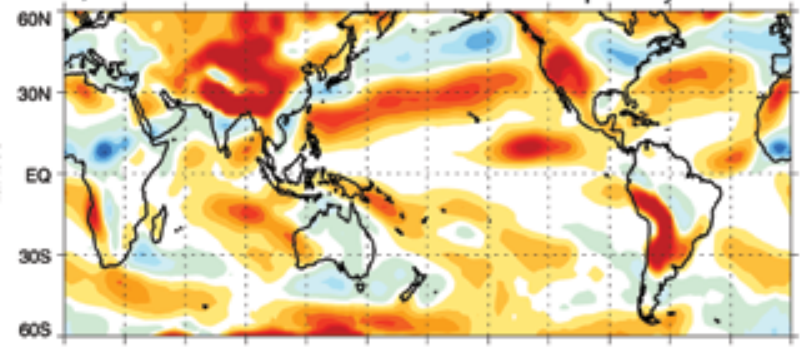

CM SOE GOE gOE 120E 150E 180 150W 120W gOW GOW soW GM Longitude

$\begin{array}{llllllllllllllll}7.5 & -6.5 & 5.5 & -4.5 & -3.5 & -2.5 & -1.5 & 0.5 & 0.50 & 1.50 & 2.50 & 3.50 & 4.50 & 5.50 & 6.50 & 7.50\end{array}$

d) ACCESS1.3-ERA-Interim cold front frequency

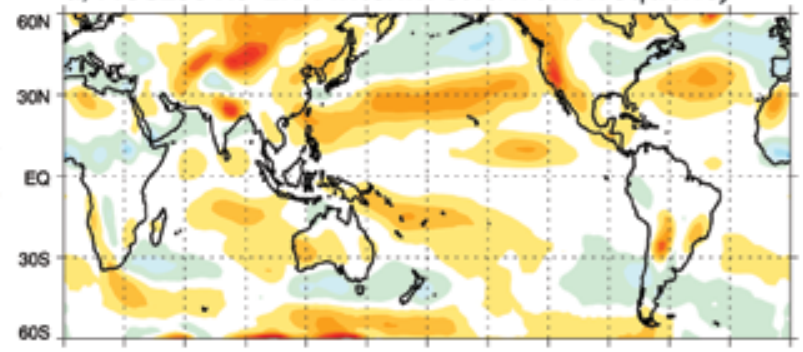

GM 30E GOE gOE 120E 150E 180 150W 120W soW GOW sow GM Longhude

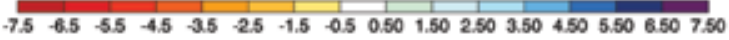

f) ACCESS1.3-ERA-Interim warm front frequency

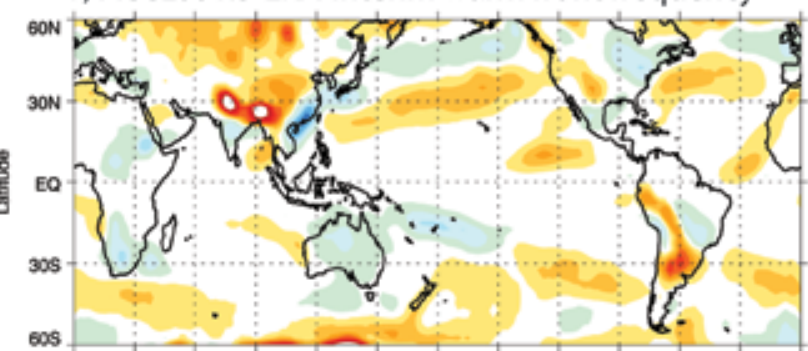

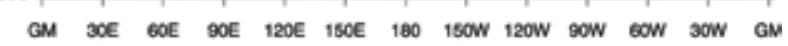
Longlude

$\begin{array}{lllllllllllllllllllll}-7.5 & -6.5 & 5.5 & -4.5 & -3.5 & -2.5 & -1.5 & -0.5 & 0.50 & 1.50 & 2.50 & 3.50 & 4.50 & 5.50 & 6.50 & 7.50\end{array}$

h) ACCESS1.3-ERA-I quasi-stationary front freq.

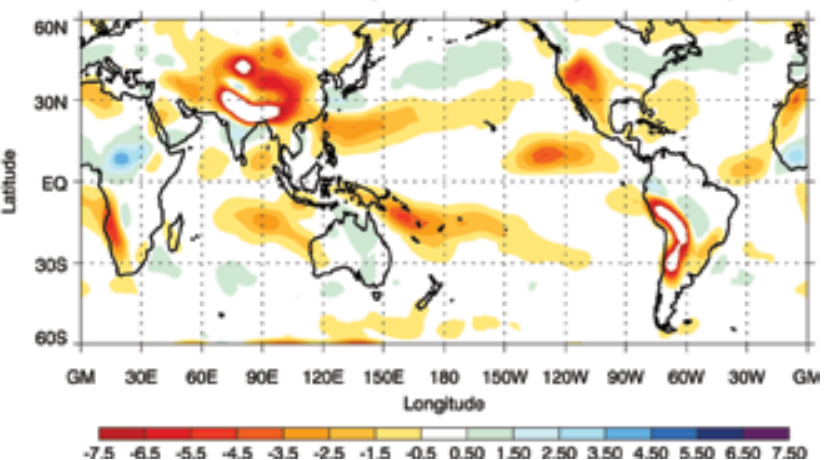


Interim. The general global pattern of mean precipitation is well captured in the model, however there is too much precipitation over the tropical regions, and especially in the western Pacific and in the Indian Ocean. These are biases which are well known in the Hadley Centre family of models (e.g. Brown et al. 2010, Martin et al. 2004). Over India, the west of the Maritime Continent and into the northwest of Australia there are large dry biases in the model. The annual mean MSLP is quite well represented in the model in most places. The MSLP is too high in the North Atlantic and North Pacific and also in the southeast Pacific. This suggests that the pressure gradient polewards of these regions is larger than observed. There is a dipole of pressure biases over the tropical Pacific that may be due to the short period of observations used. However, as mentioned previously, this does not impact the results in the rest of the paper.

\section{Front frequency}

Before the precipitation associated with fronts can be evaluated in the model, the front frequency itself is evaluated. Figure 2 shows the front frequency from ERA-Interim for the period 1997-2008 and the difference between model simulation for the full 30 years and ERA-Interim. The details of the front frequency from an observationally constrained dataset (ERA-40) have been given in Berry et al. (2011) so here we mainly focus on the comparison of the model to the ERA-Interim fields.

The global distribution for the front frequency of any type of front for ERA-Interim is shown in Fig. 2(a) and the difference between ACCESS1.3 and ERA-Interim in Fig. 2(b). In the northern hemisphere, the main storm track regions of the North Atlantic and North Pacific are quite well represented in terms of the geographical shape of the distribution but this region is shifted polewards in the model. This is consistent with the stronger pressure gradient seen in the mean climatology of MSLP in Fig. 1 and with the poleward biases in the upper level jet (not shown). The front frequency is somewhat too large to the south of Japan and over SouthEast Asia. The anomalously large number of fronts over South-East Asia can be identified as warm fronts (Fig. 2(f)). This error is consistent with the excess cyclones identified in this region in the Hadley Centre models (Greeves et al. 2007, Catto et al. 2011). Over the Pacific and Atlantic, the shifts in the maximum values of front frequency are associated with both warm fronts and cold fronts (Fig. 2(d) and 2(f)).

In the southern hemisphere, the distribution of the model's front frequency again looks reasonable. The maximum values over the Indian Ocean region are well represented in all the different types of fronts and in the total. To the south of Australia, there is a slight equatorward shift in the region of maximum front frequency so that there are higher numbers of fronts over the south of Australia. In the region of the South Pacific convergence zone (SPCZ), there are fewer cold fronts (Fig. 2(d)) and quasi-stationary fronts (Fig. 2(h)) than observed, and more warm fronts (Fig. 2(f)). However this feature is generally very well captured by the model.
Fig. 3. Colours show annual proportion (\%) of precipitation that occurs with any front within a $5^{\circ}$ box from (a) ERA-Interim and GPCP, (b) ACCESS1.3 and (c) the difference between ACCESS1.3 and the observations. The black contours show the front frequency as a percentage time that a front was located within each grid box. Polewards of $\pm 60^{\circ}$ has been cut off due to problems with the convergence of the meridians. Regions where the surface topography is higher than $1.5 \mathrm{~km}$ (850 hPa in a standard atmosphere) have been blanked out, and areas where the front frequency is less than three per cent has been shaded grey.

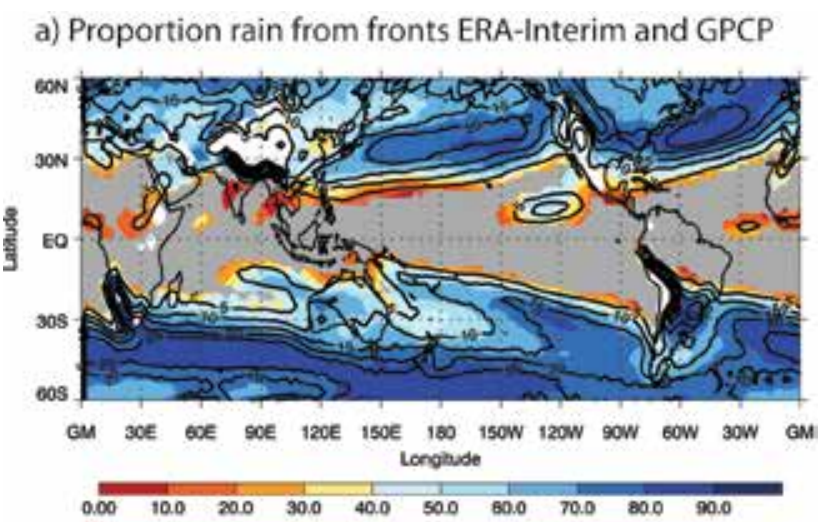

b) Proportion rain from fronts ACCESS1,3

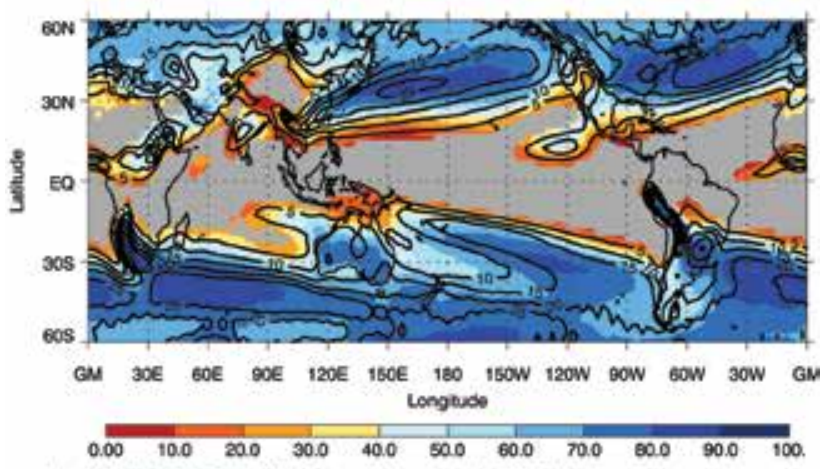

c) ACCESS1.3 - ERA-Interim and GPCP

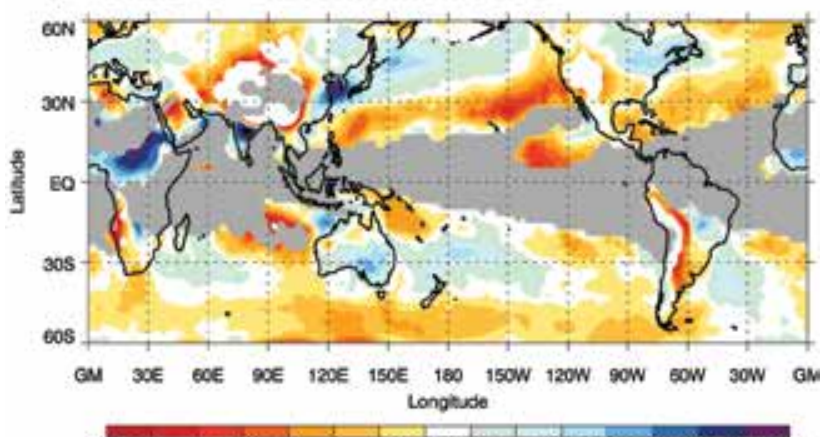

There are areas of high front frequency in the vicinity of high orography such as the Andes, the Himalayas, the Rocky Mountains and the mountains over the southern part of Africa. These fronts may be spurious due to the strong thermal gradients as the $850 \mathrm{hPa}$ contour crosses the orography. For this reason the focus of the precipitation results is on the regions of the globe unaffected by such characteristics. 
Fig. 4. Colours show annual proportion of precipitation (\%) that occurs with (a) and (b) cold fronts, (c) and (d) warm fronts, (e) and (f) quasi-stationary fronts within a $5^{\circ}$ box from $(a, c, e)$ ERA-Interim and GPCP, and (b, d, f) ACCESS1.3. The black contours show the front frequency as a percentage time that a front was located within each grid box. Polewards of $\pm 60^{\circ}$ has been cut off due to problems with the convergence of the meridians. Regions where the surface topography is higher than 1.5 $\mathrm{km}(850 \mathrm{hPa}$ in a standard atmosphere) have been blanked out, and areas where the front frequency is less than three per cent has been shaded grey.

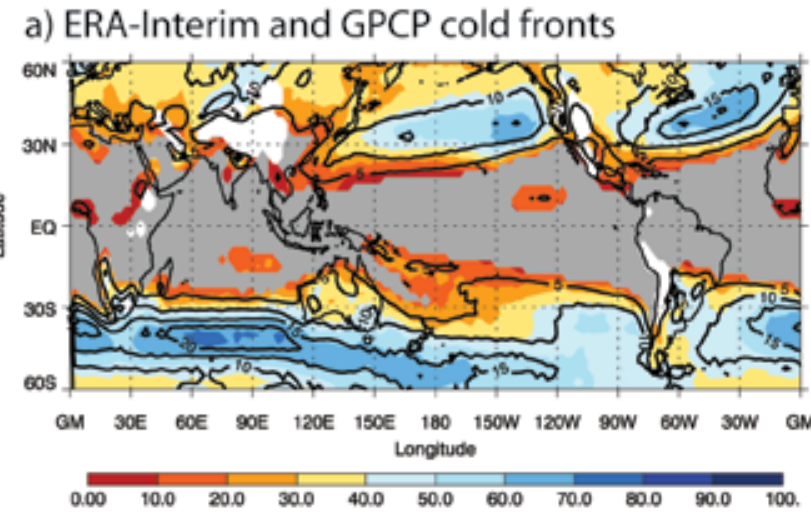

c) ERA-Interim and GPCP warm fronts

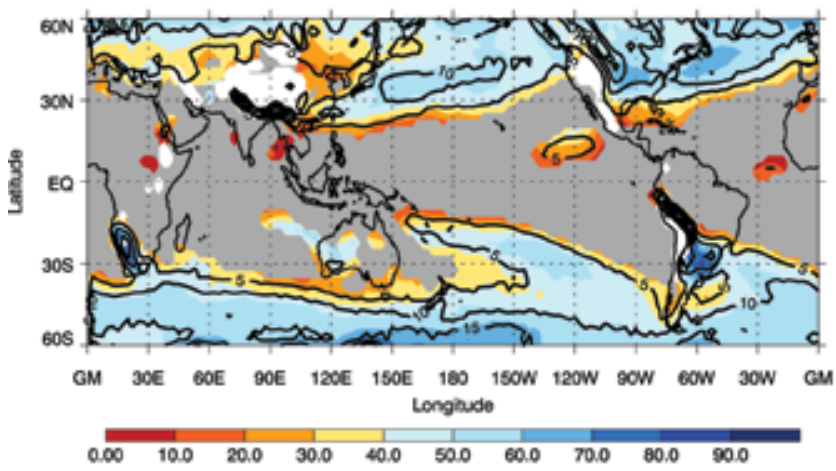

e) ERA-Interim and GPCP quasi-stationary fronts

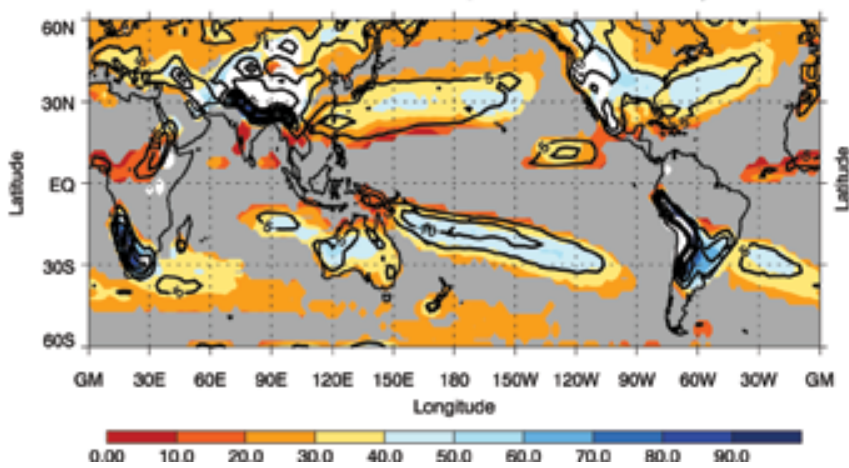

Proportion of precipitation from fronts

Maps of the annual average proportion of precipitation that has any type of associated front from the observations and the model, as well as the difference between the model and the observations, are shown in Fig. 3. In the observations (Fig. 3(a)) it can be seen that generally the areas with the highest proportion of precipitation from fronts are approximately coincident with the highest front frequencies; e.g. over the north Pacific and north Atlantic storm tracks, over the Southern Ocean storm tracks and in the region of the SPCZ. In some of these regions the proportion of precipitation

\section{b) ACCESS1.3 - ERA-Interim and GPCP}

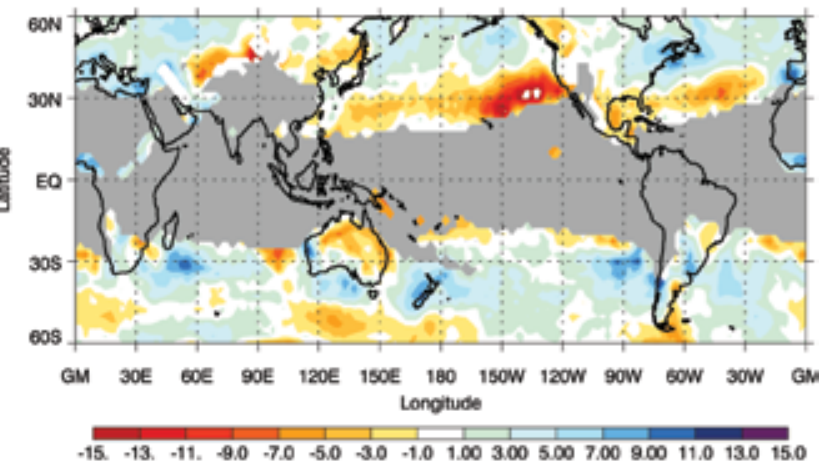

d) ACCESS1.3 - ERA-Interim and GPCP

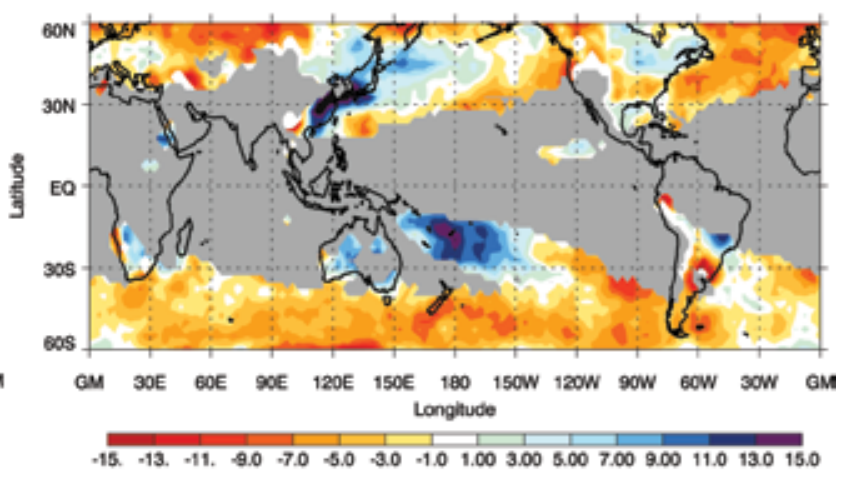

f) ACCESS1.3 - ERA-Interim and GPCP

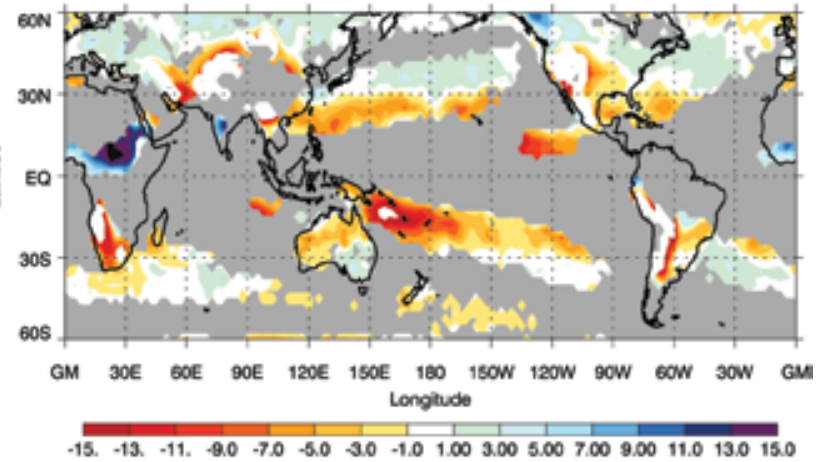

associated with any type of front is up to 90 per cent.

In the model, as in the observations, the highest proportions of precipitation associated with fronts mostly occur in the same regions as the highest front frequency. Over the northern hemisphere storm tracks, the highest proportion of precipitation associated with fronts is shifted to the north and west, consistent with the front frequency shown in Fig. 2. There are also values which are too large between China and Japan associated with the anomalously high front frequency here. Figure 4 shows the proportion of precipitation associated with each of the different types of 
fronts and Fig. 4(d) shows that the biases in the South-East Asia region are mainly associated with warm fronts.

In the southern hemisphere, again the model performs quite well. The proportion of precipitation from fronts in the Indian Ocean is too high in some places. Over the south of Australia the model shows between 60 and 80 per cent of precipitation coming from fronts which is higher than the estimate of 50-70 per cent from the observations. This is mainly associated with a greater proportion of precipitation from warm fronts (Figs 4(b) and 4(e)). The proportion of precipitation from fronts in the SPCZ region is quite well represented in the model compared to the observations in terms of the spatial structure, but there is a negative error at the northwestern end of the SPCZ mainly associated with the error in the proportion of precipitation associated with quasi-stationary fronts (Fig. 4(f)).

The performance of the model in capturing the annual average proportion of precipitation associated with fronts is summarised in Fig. 5. The average values calculated over different regions of the globe are compared between the observations and the model. Globally (between $60^{\circ} \mathrm{S}$ and $60^{\circ} \mathrm{N}$ ) the average proportion of precipitation from any type of front and from the individual types of fronts agrees extremely well between the observations and the model, although the model very slightly underestimates the values in all regions. The highest average proportion of precipitation from fronts is in the mid-latitudes, and the lowest is in the tropics. In these regions the model captures the values very well overall with values within two per cent of the observed values.

\section{Average precipitation from fronts}

Figure 6 shows the annual average daily precipitation within a grid box when there is any type of front within the $5^{\circ}$ search box, and when there is no front within the search box for both the observations and the model. This measure can be thought of as the intensity of frontal (or non-frontal) precipitation. The intensity of non-frontal precipitation shows maximum values in the tropics, as expected, with maximum average values of about $10 \mathrm{~mm} /$ day. In the SPCZ region where there are warm waters, there are also high intensities of non-frontal precipitation of between 5 and 8 $\mathrm{mm}$ /day. Over the major northern hemisphere storm track regions the daily precipitation when there is no front present is about $3-4 \mathrm{~mm} /$ day. The model is generally able to capture the spatial pattern of the non-frontal precipitation intensity quite well (Fig. 6(b)). In most regions the intensity of nonfrontal precipitation is generally too low, but in parts of the tropics is too high. The biases in the non-frontal precipitation look similar to those in the annual mean climatology of precipitation in the model, showing too intense precipitation in the western Pacific and Indian Ocean regions.

The highest values of frontal precipitation intensity (Fig. 6(c)) are found over the warm current regions at the western ends of the northern hemisphere storm tracks, over the SPCZ region, and to the east of South America with daily
Fig. 5. Average proportion of precipitation associated with fronts (per cent) taken over seven different regions: global $\left(60^{\circ} \mathrm{S}\right.$ to $\left.60^{\circ} \mathrm{N}\right)$, mid-latitudes $\left(30^{\circ} \mathrm{S}\right.$ to $60^{\circ} \mathrm{S}$ and $30^{\circ} \mathrm{N}$ to $60^{\circ} \mathrm{N}$ ), tropics $\left(30^{\circ} \mathrm{S}\right.$ to $30^{\circ} \mathrm{N}$ ), land (within $60^{\circ} \mathrm{S}-60^{\circ} \mathrm{N}$ ), sea (within $60^{\circ} \mathrm{S}$ to $60^{\circ} \mathrm{N}$ ), northern hemisphere $\left(0-60^{\circ} \mathrm{N}\right)$, and southern hemisphere $\left(0-60^{\circ} \mathrm{S}\right)$. See legend for the meaning of the symbols.

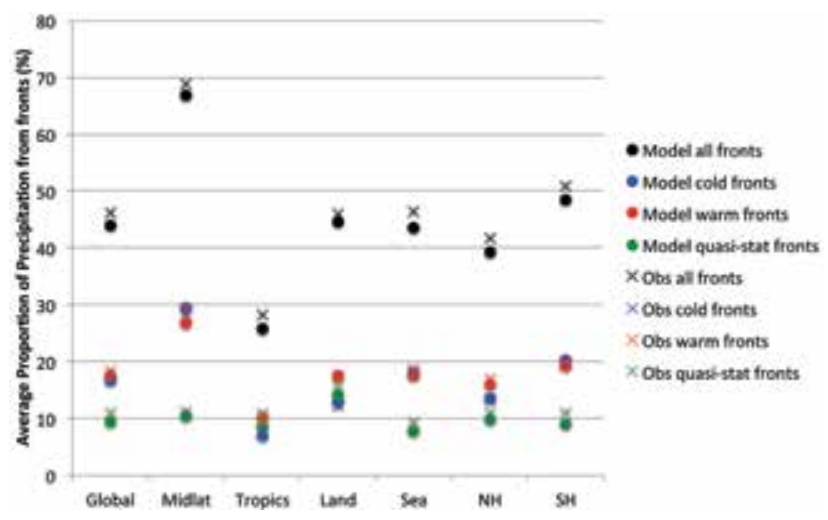

precipitation values of up to $10 \mathrm{~mm} /$ day. In these regions the frontal precipitation intensity is higher than the non-frontal intensity. Over the southern parts of Australia the average frontal precipitation intensity is about $2 \mathrm{~mm}$ /day while in the north it is closer to $8 \mathrm{~mm} /$ day. Over the main Southern Ocean storm track region where a large proportion of precipitation is associated with fronts, the average intensities are between 4 and $5 \mathrm{~mm}$ /day compared to $2-3 \mathrm{~mm} /$ day for non-frontal precipitation in the same region. The model captures quite well the spatial distribution of the frontal precipitation intensity with maxima in roughly the same regions as in the observations. The values over the SPCZ and the Kuroshio Current region are about $2 \mathrm{~mm}$ /day lower than the observations (Fig. 6(d)). Over Australia the model shows lower than observed frontal and non-frontal precipitation intensities, particularly in the northwest.

Figure 7 shows the intensity of frontal rain split into the three frontal types. Warm frontal rain is of the highest intensity in the observations and the model. The biases in the model associated with too weak intensity come from both the cold front and the warm front components of the daily precipitation. In the SPCZ region, there are competing biases in the model with too low intensity precipitation from quasi-stationary fronts and too high intensity precipitation from warm fronts.

Figure 8 summarises the frontal and non-frontal precipitation intensities for different regions. In all regions except the tropics, the model underestimates the intensity of frontal and non-frontal rain. The largest bias occurs in the mid-latitudes. The errors in the model intensity appear smaller over the oceans than over land (and therefore smaller in the southern hemisphere than the northern hemisphere); however, it is worth keeping in mind the lower confidence in the observational estimates over the oceans due to the lack of gauge data to verify and constrain the satellite estimates. 
Fig. 6. Annual average daily precipitation within a grid box from observations (a), (c) and the difference between model and observations (b), (d) when (a), (b) no front is present, and (c), (d) any type of front is present within the $5^{\circ}$ search area (mm/day).

a) ERA-Interim/GPCP non-frontal precip intensity

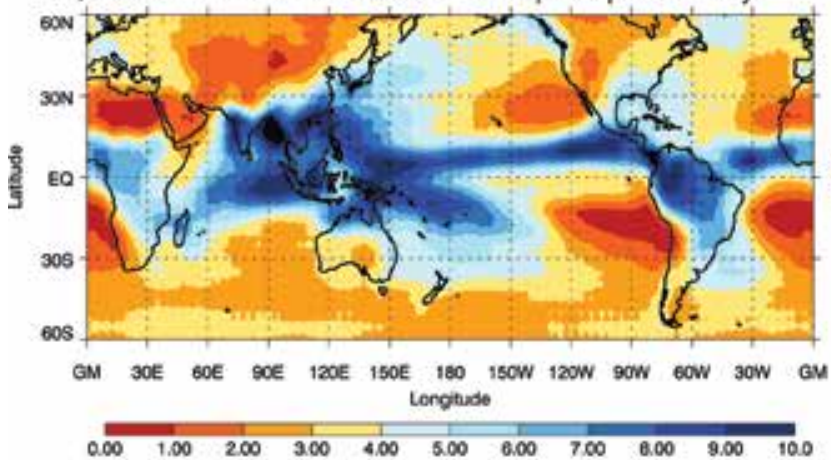

c) ERA-Interim/GPCP frontal precip intensity

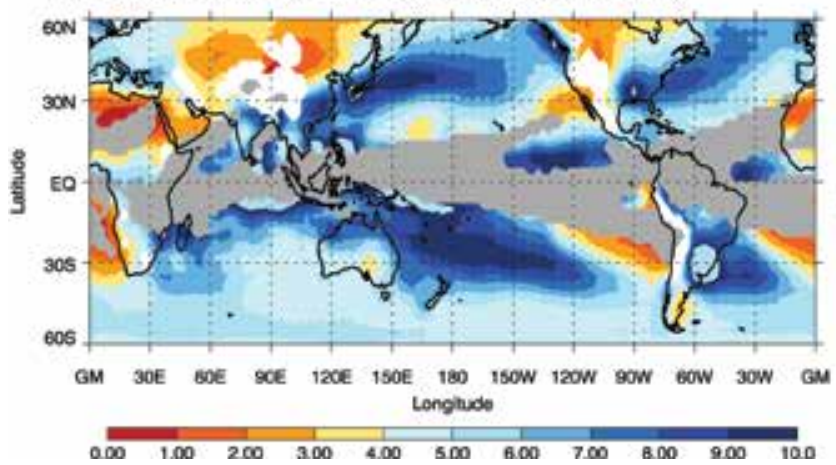

Precipitation intensities

Frequency distributions of the daily precipitation when there are or are not fronts present within the $5^{\circ}$ search area from each grid box have been constructed and are shown in Fig. 9. Only precipitation intensities over $1 \mathrm{~mm}$ /day have been included as in Sun et al. (2006) and Brown et al. (2010) and the histograms have been split into two graphs, one showing the lower intensities and the other showing the much more rare very high intensities. Since there are a different number of years being analysed for the observations and the model, the frequency has been divided by the number of years to give a frequency per year for each of the daily precipitation bins. Considering first the histograms of the global daily precipitation (Fig. 9(a) and (b)), the total number of occurrences of precipitation between $1 \mathrm{~mm}$ and $10 \mathrm{~mm}$ (the 'light' category in Sun et al. (2006) and Brown et al. (2010)) when there is no front present is lower than when there is any type of front present for both the observations and the model. For rainfall above $10 \mathrm{~mm}$ the frequency is higher for no-fronts than fronts (approximately 17 per cent more). This indicates that globally, if it rains when there is no front present, the precipitation is more likely to be heavy than when there is a front present. The total frequency of warm and cold front events is similar, but there are higher frequencies of heavier precipitation associated with warm fronts. There are lower total frequencies of rain from quasi-stationary fronts. There are much lower frequencies
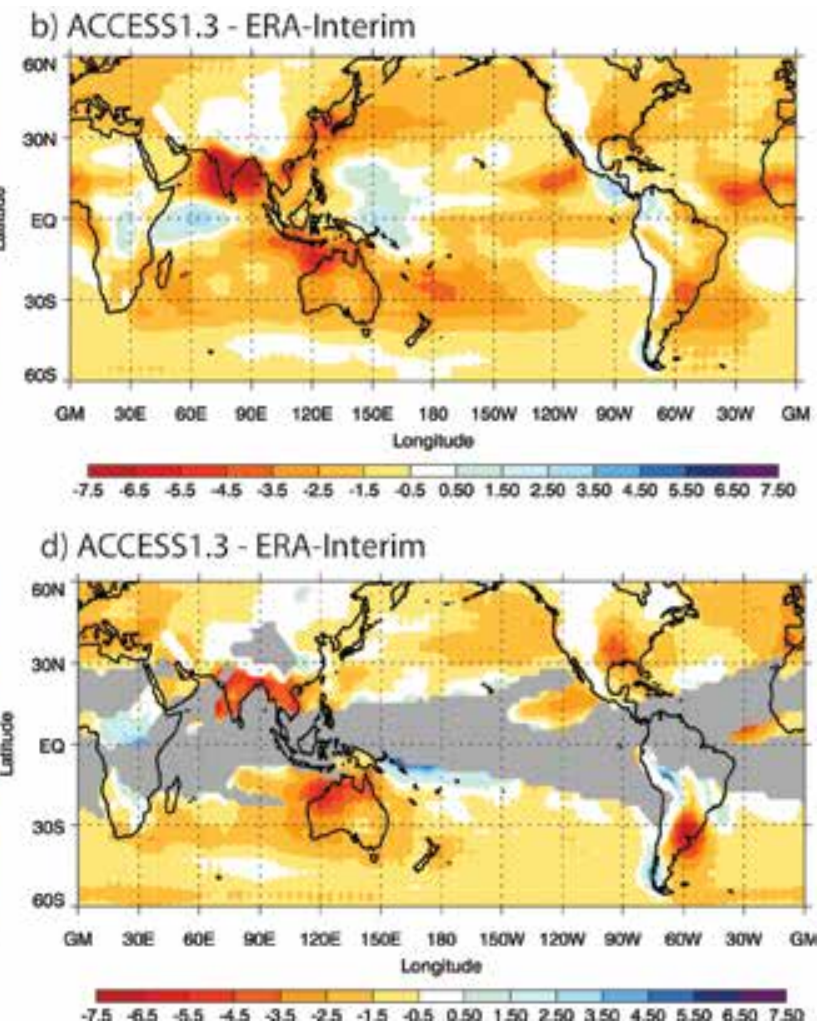

of precipitation intensities between $1 \mathrm{~mm}$ and $25 \mathrm{~mm}$ associated with quasi-stationary fronts, but for intensities above that, the cold fronts and quasi-stationary fronts have similar frequency distributions. The ACCESS1.3 simulation is able to distinguish the differences between the different types of fronts, with higher frequencies of very heavy precipitation with no front present, and higher frequencies of heavy precipitation (above $10 \mathrm{~mm}$ ) with warm fronts compared to quasi-stationary and cold fronts. Similar to previous studies, the model overestimates the frequency of frontal precipitation events with light precipitation (between $1 \mathrm{~mm}$ and $10 \mathrm{~mm} /$ day) by about 85 per cent globally. It underestimates the frequency of frontal heavy precipitation events (over $10 \mathrm{~mm} /$ day) by about seven per cent, but as can be seen in Fig. 9(b), there are a larger number of very high intensity frontal and non-frontal precipitation events in the model compared to the observations. However, these very intense precipitation events constitute a tiny proportion of all grid-point precipitation events.

In the mid-latitudes (Fig. 9(c) and (d)) for the observations it can be seen that the highest frequency of precipitation at any intensity is associated with fronts. For the light precipitation (between $1 \mathrm{~mm} /$ day and $10 \mathrm{~mm} /$ day) there are similar frequencies associated with cold and warm fronts, but for intensities greater than $10 \mathrm{~mm} /$ day there are higher frequencies associated with warm fronts. The model again captures the differences between the distributions 
Fig. 7. Annual average daily precipitation within a grid box from observations (a, $c$ and e) and the difference between model and observations $(b, d$, and $f)$ when $(a, b)$ cold front, $(c, d)$ warm front, and $(e, f)$ quasi-stationary front is present within the $5^{\circ}$ search area ( $\mathrm{mm} /$ day).

a) ERA-Interim/GPCP cold frontal precip intensity

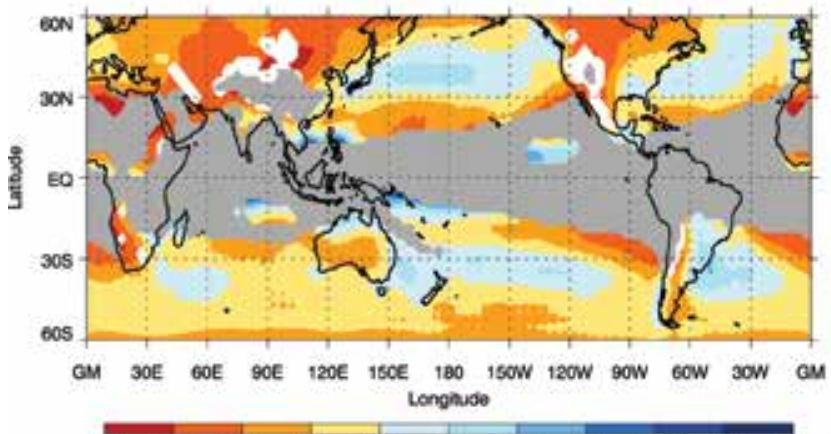

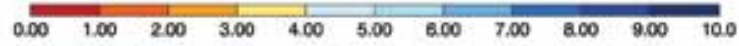

c) ERA-Interim/GPCP warm frontal precip intensity

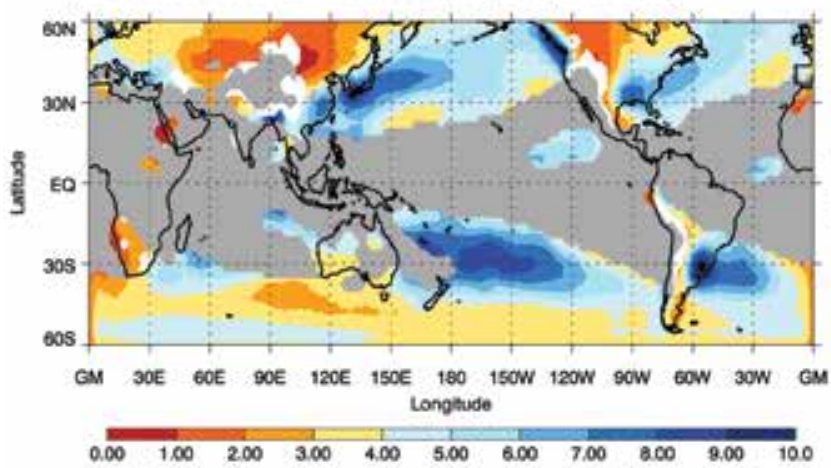

e) ERA-1/GPCP quasi-stationary frontal precip intensity

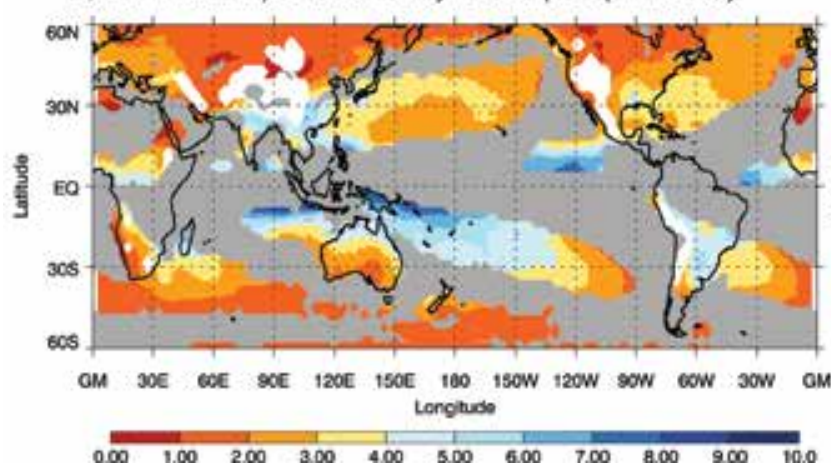

of the precipitation from frontal types with higher daily precipitation from fronts rather than no fronts. In the midlatitudes the model overestimates the frequency of light frontal precipitation by approximately 28 per cent and underestimates the frequency of heavy frontal precipitation events by nine per cent (which is larger than the global value).

In the tropics (Fig. 9(e) and (f)) there are higher numbers of precipitation events with no front present than with a front present. This is as expected due to much of the precipitation being from convective systems rather than large-scale frontal systems. More extreme high precipitation events occur with no front present, although relative to the total number of corresponding events, the distributions of the no- b) ACCESS1.3 - ERA-Interim cold frontal precip intensity

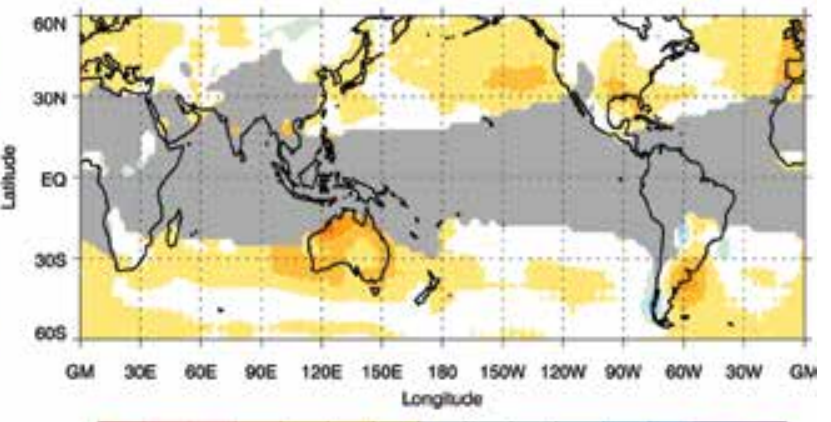

$\begin{array}{lllllllllllllllll}-7.5 & -6.5 & 5.5 & 4.5 & 3.5 & 2.5 & -1.5 & 0.5 & 0.50 & 1.50 & 2.50 & 3.50 & 4.50 & 5.50 & 6.50 & 7.50\end{array}$ d) ACCESS1.3 - ERA-Interim warm frontal precip intensity

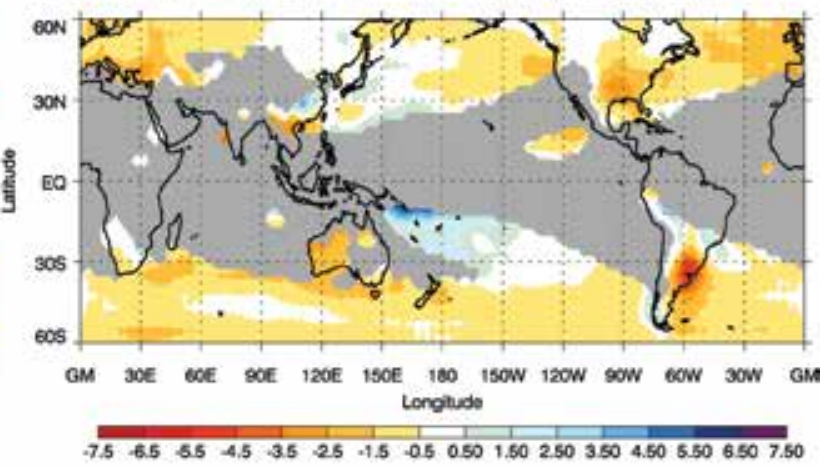

f) ACCESS1.3 - ERA-Interim quasi-stat frontal precip intensity

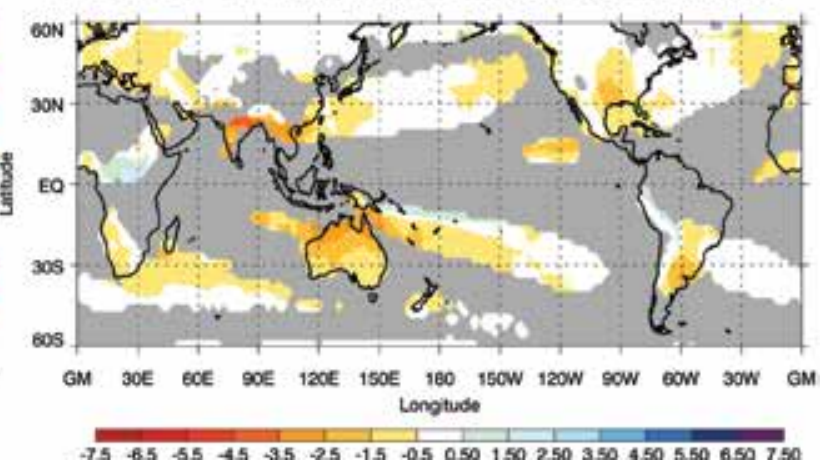

front and any-front frequencies are very similar. The model overestimates the frequency of the lighter precipitation events (below $20 \mathrm{~mm}$ ) and underestimates the frequency of heavy frontal rain events in the tropics, but only by about one per cent. The histogram shows that in the tropics there are too many very intense precipitation events (above 50 $\mathrm{mm}$ /day) both with or without fronts, however these events are very rare in both the observations and the model.

\section{Error decomposition}

The method of relating fronts to precipitation to evaluate a climate model can be used to decompose the total precipitation error in the model. Similar methods have been used to investigate errors in clouds and precipitation 
Fig. 8. As for Fig. 5 but for precipitation from fronts (mm/day).

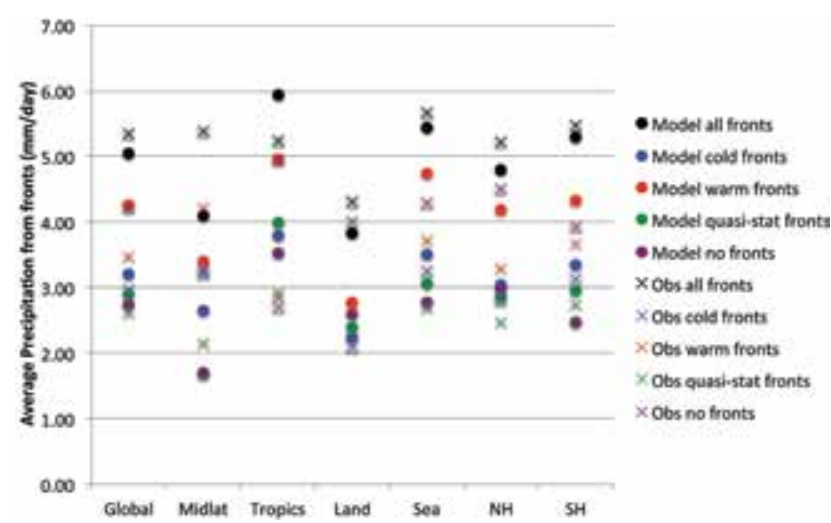

in climate models (Williams and Tselioudis 2007; Brown et al. 2010; Stephens et al. 2010) and to look at trends and future changes in clouds and precipitation (Bony et al. 2004, Williams and Tselioudis 2007, Catto et al. .2012b, Moise et al. 2012). We can think of the presence of fronts as a type of regime, with the other regime being the no-front case. In this way the total precipitation error can be broken down into the components related to the frequency of occurrence of the regime (front or no-front) and to the intensity of precipitation associated with that regime. The total error $E_{p}$ can be represented as:

$E_{p}=P_{m}-P_{o}$

$E_{p}=F_{f, m} I_{f, m}+F_{n f, m} I_{n f, m}-F_{f, o} I_{f, o}-F_{n f, o} I_{n f, o}$

$E_{p}=\Delta F_{f} I_{f, o}+F_{f, o} \Delta I_{f}+\Delta F_{f} \Delta I_{f}+\Delta F_{n f} I_{n f, o}+F_{n f, o} \Delta I_{n f}+\Delta F_{n f} \Delta I_{n f}(3)$

Fig. 9. Frequency distributions of precipitation from fronts when the precipitation is greater than $1 \mathrm{~mm}$. Bins are $2 \mathrm{~mm}$ and the frequency is given per year. Lower intensities shown by (a), (c), (e), and higher intensities shown by (b), (d), (f), for (a) and (b) global $\left(60^{\circ} \mathrm{S}-60^{\circ} \mathrm{N}\right)$, (c) and (d) mid-latitudes, and (e) and (f) tropics. Here the solid lines represent the observations and the dashed lines represent the model.

a) Global (60S-60N) 1-30mm/day
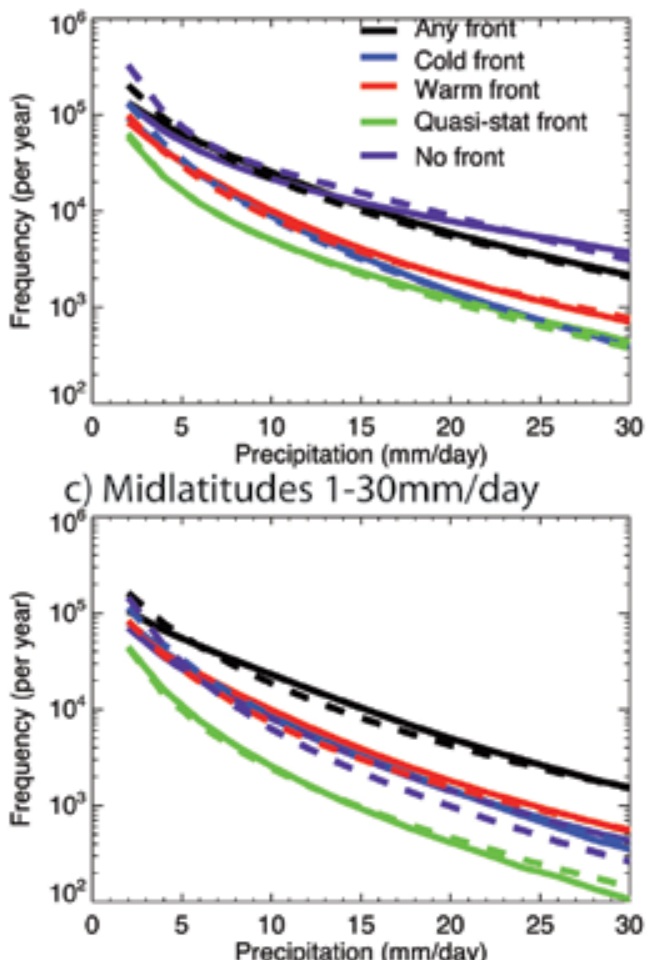

e) Tropics $1-30 \mathrm{~mm} /$ day

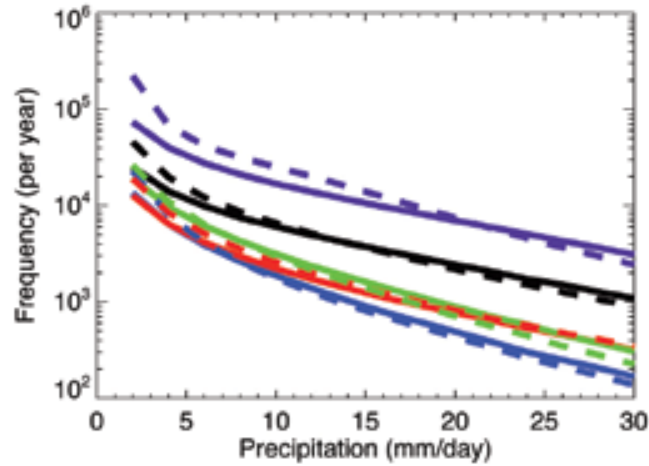

b) Global $(60 \mathrm{~S}-60 \mathrm{~N}) 30-150 \mathrm{~mm} /$ day

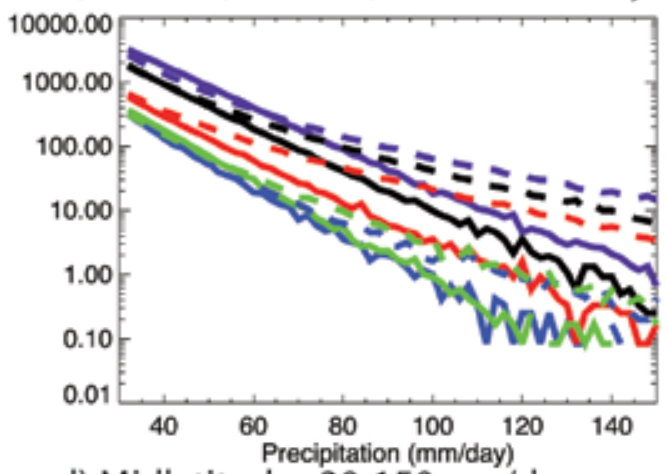

d) Midlatitudes $30-150 \mathrm{~mm} /$ day

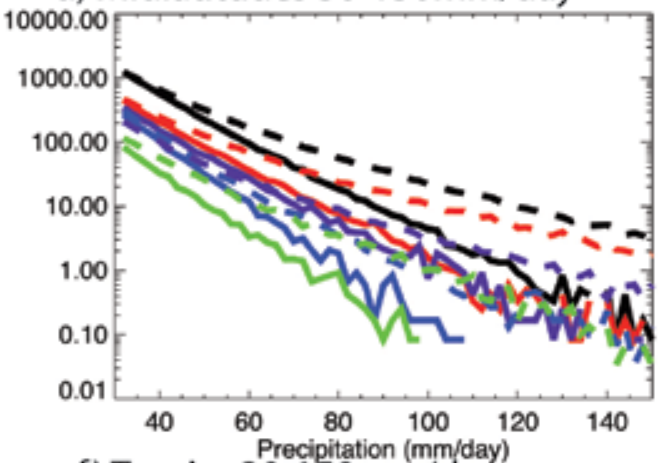

f) Tropics $30-150 \mathrm{~mm} /$ day

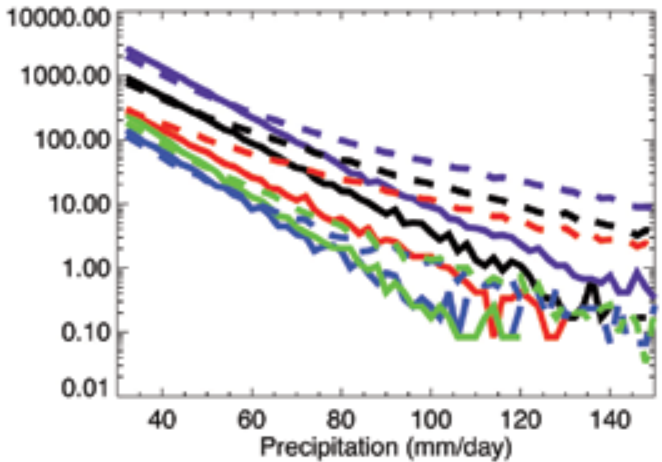


where the subscript, $f$ represents the frontal regime, $n f$ represents the no-front regime, $m$ represents the model and $o$ the observations. $F$ is the frequency of occurrence of fronts when there is rain and $I$ is the intensity of precipitation associated with each regime. The terms $\Delta F$ and $\Delta I$ represent the difference between the model and the observations for the frequency and intensity respectively.

Figure 10 shows the absolute precipitation error from each of the six terms in Eqn 3. The error associated with the frequency of occurrence of each of the regimes (terms one and four shown in Fig. 10(a) and (d)) contribute mostly positive errors to the total, especially for the no-front regime. This confirms that the climate model generally rains too frequently. In the tropics, the largest error contributions come from the no-front regime. This is understandable as there are very few fronts identified in the tropics. The dry bias over the west of the Maritime Continent and the wet biases over the western Indian Ocean and western Pacific are mostly related to errors in the intensity of precipitation when there is no front present (Fig. 10(e) and (f)). The dry bias over the northwest of Australia has contributions from the intensity of precipitation when there is and is not a front present. In some parts of the mid-latitude storm tracks the errors in the frequency of occurrence of the regimes and the intensity of precipitation seem to compensate each other to produce generally small total errors. This error decomposition again confirms the too frequent too light error in precipitation in the model.

It can be concluded that the errors in rainfall associated with the no-front regime are the largest contributor to the

Fig. 10. Error decomposition showing the absolute precipitation error ( $\mathrm{mm} /$ day) contributing to the total error (shown in Fig. 1) from each of the terms in Eqn 3. The errors associated with the frontal regime are shown in (a)-(c) and the errors associated with the no-front regime are shown in (d)-(f). (a) $\Delta F_{f \rho o^{\prime}}$ (b) $F_{f, o} \Delta I_{f}$, (c) $\Delta F_{f} \Delta I_{f}$, (d) $\Delta F_{n f} I_{n f, o^{\prime}}$ (e) $F_{n f, o} \Delta I_{n f}$, and (f) $\Delta F_{n f} \Delta I_{n f}$.

a) Error term 1: $\Delta F_{f} I_{f c}$

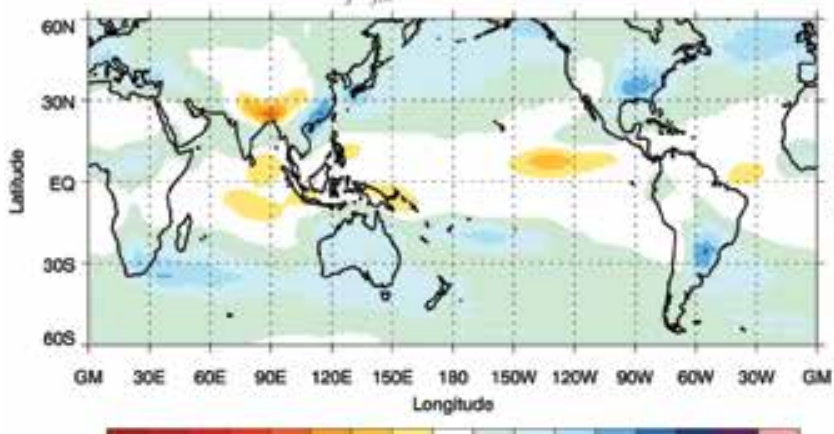

$-4.25-3.75-3.25-2.75-2.25-1.75-1.25-0.75-0.250 .250 .751 .2551 .752 .252 .753 .253 .754 .25$

b) Error term 2: $F_{f, 0} \Delta I_{f}$

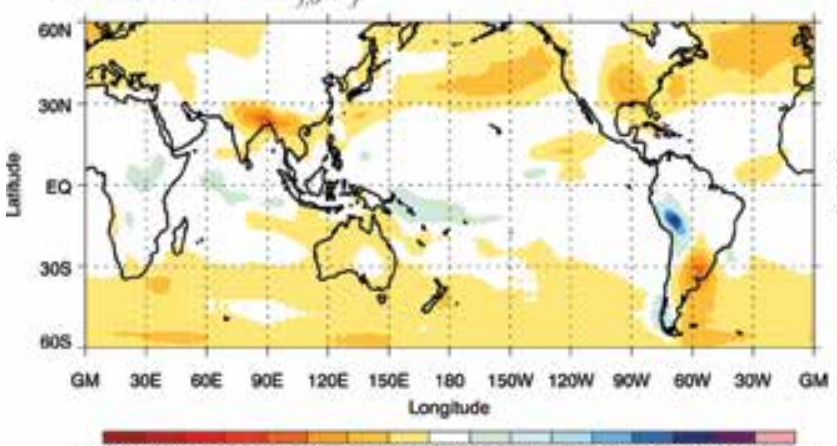

$4.25-3.75-325-2.75-2.25-1.75-1.250 .75-0.250 .250 .751 .251 .752 .252 .753 .253 .754 .25$

c) Error term 3: $\Delta F_{f} \Delta I_{f}$

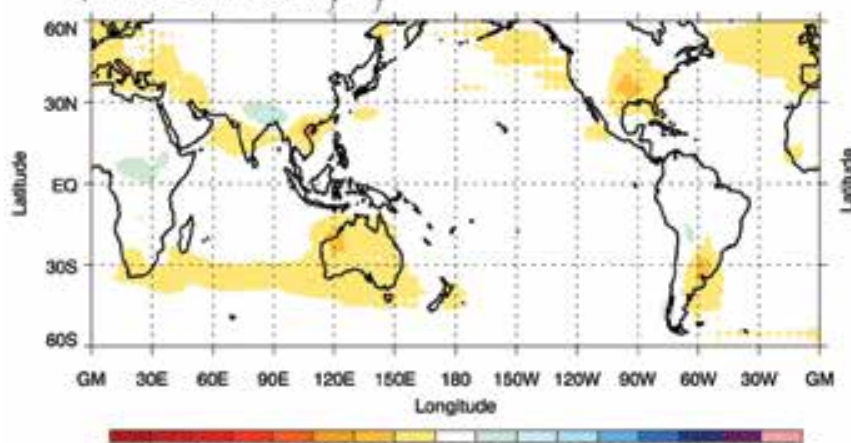

$-4.25-3.75-325-275-2.25-1.75-1.250 .75-0.250250751 .251752 .752753 .253754 .25$ d) Error term 4: $\Delta F_{i} I_{\text {rfo }}$

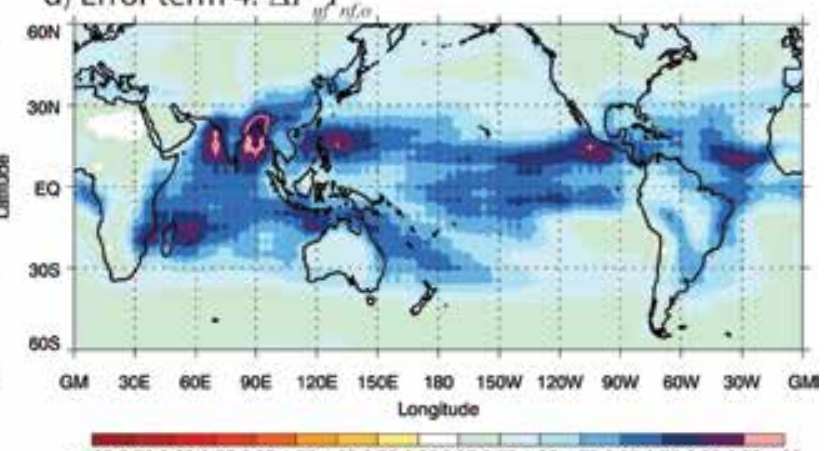

$-4.25-3.75-3.25-2.75 \cdot 2.25-1.75-1.25-0.75-0.250 .250 .751 .251 .752 .252 .753 .253 .754 .25$

e) Error term 5: $F_{\text {we }} \Delta l_{\text {rif }}$

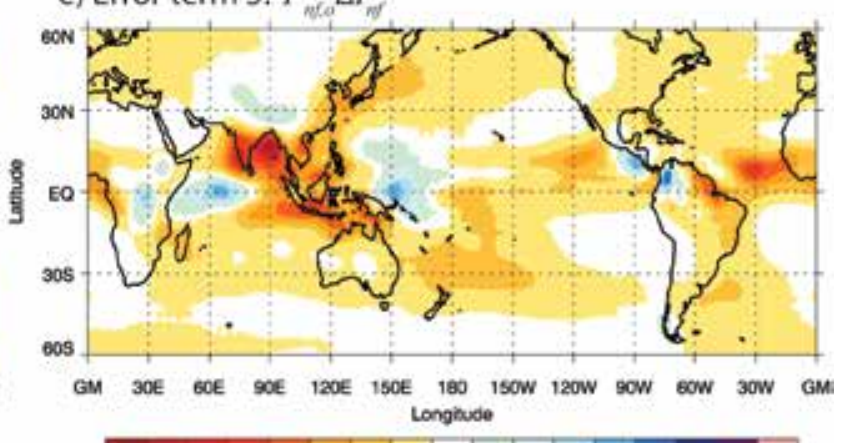

4.25-3.75-3.25-2.75-2.25-1.75-1.25-0.75-0.250.25 0.75 1.25 1.75 2.25 2.75 2.25 3.75 4.25

f) Error term 6: $\Delta F_{n j} \Delta I_{n i}$

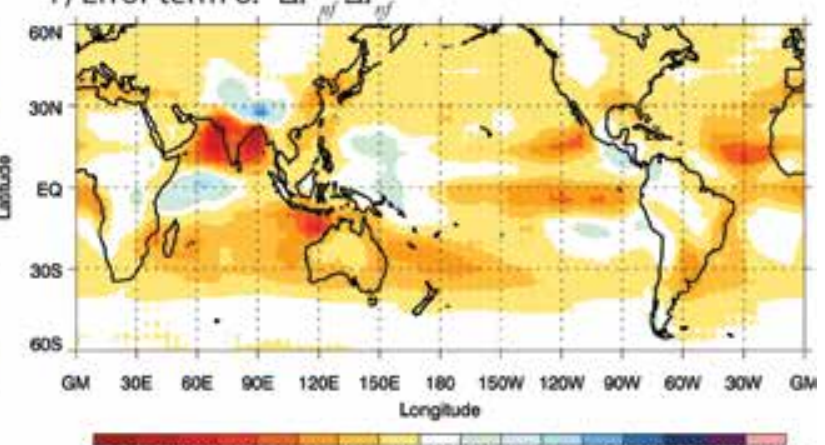

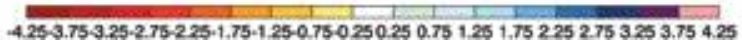


Fig. 11. Percentage of average daily precipitation from fronts that comes from large scale precipitation in ACCESS1.3. Areas where the front frequency is less than three per cent has been shaded grey.

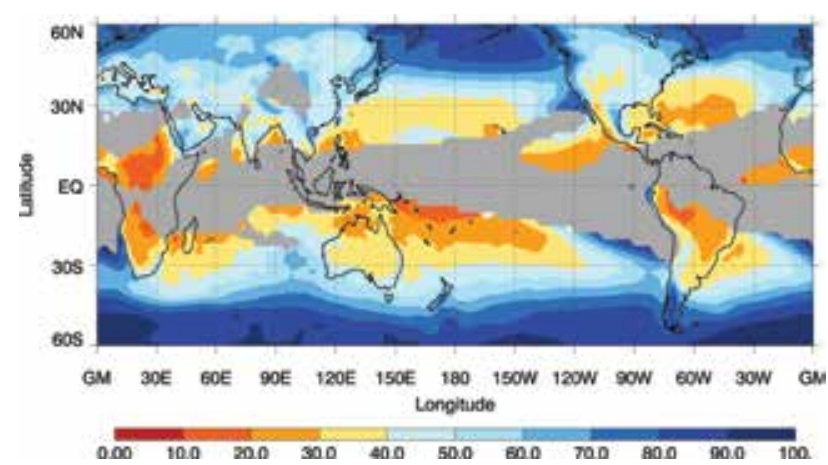

total rainfall errors. This suggests that the convective rainfall may be an important consideration in these errors. The location of the largest errors in the average daily precipitation over the warm waters also implies that convection may be the culprit. Figure 11 shows the percentage of the average daily precipitation associated with fronts that comes from the large-scale precipitation scheme in the model. The regions where the largest errors in daily precipitation appear are the regions where the highest proportion of that precipitation is produced by the convective parameterisation.

\section{Discussion and conclusions}

Since precipitation globally and regionally is of major socioeconomic consequence, it is vital that climate models are able to represent not only the mean climatology of precipitation, but also the precipitation intensities and the reasons for precipitation events. Fronts play an important role in delivering precipitation and can be associated with heavy rain and flooding. In this paper the atmosphere component of ACCESS1.3 has been evaluated in terms of precipitation associated with fronts. This has been performed using the method of Berry et al. (2011) to identify fronts in reanalysis and model data and combining the fronts with daily rainfall as in Catto et al (2012a). The front frequency and proportion of precipitation from fronts, as well as the global distribution of precipitation intensities associated with fronts have been evaluated. The total precipitation error has been decomposed into components associated with errors in the frequency and intensity of precipitation within the two regimes of 'front' and 'no-front' in order to understand more fully from where the precipitation biases stem.

It has been found that ACCESS1.3 generally performs well in representing the spatial pattern of front frequency in many regions. However, the model shows a poleward and westward shift of the northern hemisphere storm tracks, too many fronts over South-East Asia and over Australia. As a consequence, in the regions with higher than observed front frequencies, the contribution to rainfall from fronts is too large. This is confirmed by the decomposition of the errors in these regions showing a large contribution from errors in front frequency. The average daily precipitation from fronts as well as the precipitation when there is no front present is underestimated by the model in all regions. This agrees with the results of Brown et al. (2010) for the older ACCESS model (version 1.0) where it was found that the precipitation intensity over land was underestimated. Previous studies have shown that climate models tend to overestimate the frequency of light precipitation (Sun et al. 2006; Brown et al. 2010; Wilcox and Donner 2007; Stephens et al. 2010). Our results are consistent with these previous studies. The spatial pattern of daily precipitation from fronts is reproduced in the model, however the values are too high in the tropics and over the regions of warmer waters. The error decomposition shows that the no-front rainfall contributes the largest errors in these regions and so it is likely that the errors are mainly produced by the representation of the sub grid-scale convection. At present it is not possible to evaluate the convective and large-scale precipitation separately as there is currently no way to decompose global observational estimates of precipitation into these components.

This study has demonstrated a novel way to evaluate the precipitation characteristics in climate models. The use of a process- and regime-oriented evaluation gives more insight into the causes of precipitation biases in the model. We have found that the precipitation errors are largely driven by the no-front precipitation regime, but the error decomposition highlights considerable compensating errors in the model. How precipitation, and particularly precipitation extremes, will change in the future is of great interest. In order to be able to generate projections of precipitation changes in which we can have confidence, it is essential that the precipitation characteristics in the model are evaluated and understood. An evaluation of the new suite of climate models available from the Coupled Model Intercomparison Project version 5 (CMIP5) using the techniques developed here, especially the error decomposition, will be the subject of a future study.

\section{Acknowledgments}

This study was supported by the Australian Research Council through the Linkage Project Grant LP0883961, the Discovery Project Grant DP0877417, and the ARC Centre of Excellence for Climate System Science (grant CE110001028). The front identification algorithm was kindly provided by Gareth Berry. The authors would also like to thank the two anonymous reviewers for their helpful comments.

\section{References}

Adler, R.F., et al. 2003. The Version-2 Global Precipitation Climatology Project (GPCP) Monthly Precipitation Analysis (1979-present). J. Hydrometeor., 4, 1147-67.

Bengtsson, L., Hodges, K.I. and Keenlyside, N. 2009. Will extra-tropical storms intensify in a warmer climate?, J. Clim., 22, 2276-301.

Berry, G., Reeder, M.J. and Jakob, C. 2011. A global climatology of atmospheric fronts. Geophys. Res. Lett., 38, doi:10.1029/2010GL046 451. 
Bi, D., et al. 2013. The ACCESS Coupled Model: Description, Control Climate and Evaluation. Aust. Met. Oceanogr. J., 63, 41-64.

Bolvin, D.T., Adler, R.F., Huffman, G.J., Nelkin, E.J. and Poutianinen, J.P 2009. Comparison of GPCP monthly and daily precipitation estimates with high-latitude gauge observations. J. Appl. Meteorol. Climatol., 48, 1843-57.

Bony, S., Dufresne, J.L., Le Treut, H., Morcrette, J.J. and Senior, C.A. 2004. On dynamic and thermodynamic components of cloud changes. Clim. Dyn., 22, 71-86.

Brown, J.R., Jakob, C. and Haynes, J.M. 2010. An evaluation of rainfall frequency and intensity over the Australian region in a global climate model. J. Clim., 23, 6504-25.

Catto, J.L., Jakob, C., Berry, G. and Nicholls, N. 2012a. Relating global precipitation to atmospheric fronts. Geophys. Res. Lett., 39, DOI: 10.1029/2012GL051736.

Catto, J.L., Jakob, C. and Nicholls, N. 2012b. The influence of changes in synoptic regimes on north Australian wet season rainfall trends. J. Geophys. Res., 117, DOI: 10.1029/2012JD017472.

Catto, J.L., Shaffrey, L.C. and Hodges, K.I. 2010. Can climate models capture the structure of extratropical cyclones? J. Clim., 23, 1621-35.

Catto, J.L., Shaffrey, L.C. and Hodges, K.I. 2011. Northern Hemisphere extratropical cyclones in a warming climate in the HiGEM high-resolution climate model. J. Clim., 24, 5336-52, DOI: 10.1175/2011JCLI4181.1.

Champion, A.J., Hodges, K.I., Bengtsson, L.O., Keenlyside, N.S. and Esch, M. 2011. Impact of increasing resolution and a warmer climate on extreme weather from Northern Hemisphere extratropical cyclones. Tellus, 63A, 893-06.

Dai, A. 2006. Precipitation characteristics in eighteen coupled climate models. J. Clim., 19, 4605-30.

Dee, D.P., et al. 2006. The ERA-Interim reanalysis: configuration and performance of the data assimilation system. Q. J. R. Meteorol. Soc., 137, 553-97.

Greeves, C.Z., Pope, V.D., Stratton, R.A. and Martin, G.M. 2007. Representation of Northern Hemisphere winter storm tracks in climate models Clim. Dyn., 28, 683-702, DOI 10.1007/s00 382-006-0205-x.

Hewitt, H.T., Copsey, D., Culverwell, I.D., Harris, C.M., Hill, R.S.R., Keen, A.B., McLaren, A.J. and Hunke, E.C. 2011. Design and implementation of the infrastructure of HadGEM2: the next generation Met Office climate modelling system. Geosci. Model Dev., 4, 223-253, doi:10.5194/ gmd-4-223-2011.

Hewson, T. D. 1998: Objective fronts. Meteorol. Appl., 5, 37-65.

Huffman, G.J., Adler, R.F., Morrissey, M., Bolvin, D.T., Curtis, S., Joyce, R., McGavock, B. and Susskind, J. 2001. Global precipitation at one-degree daily resolution from multi- satellite observations. J. Hydrometeor., 2, 36-50.

Kowalczyk, E.A., Wang, Y.P., Law, R.M., Davies, H.L., McGregor, J.L. and Abramowitz, G. 2006. The CSIRO Atmosphere Biosphere Land Exchange (CABLE) model for use in climate models and as an offline model. CSIRO Marine and Atmospheric Research paper 013

Lavers, D.A., Allan, R.P., Wood, E.F., Villarini, G., Brayshaw, D.J. and Wade, A.J. 2011. Winter floods in Britain are connected to atmospheric rivers. Geophys. Res. Lett., 38 (L23803), doi:10.1029/2011GL049 783.

Martin, G.M., Inness, P.M., Yang, G.-Y., Hoskins, B.J. and Slingo, J.M. 2004. Tropical performance of HadGAM1. Tech. Rep. 51, Met Office Hadley Centre, 13 pp pp. [Available online at http://www.metoffice. gov.uk/publications/HCTN/HCTN 51.pdf.]

McPhee, J. and Margulis, S.A. 2005. Validation and error characterization of the GPCP-1DD precipitation product over the contiguous United States. J. Hydrometeor., 6, 441-59.

Mills, G.A. and Wu, B.-J. 1995. The 'Cudlee Creek' flash flood - an example of synoptic-scale forcing of a mesoscale event. Aust. Meteorol. Mag., 44, 201-18.

Moise, A.F., Colman, R.A., and Brown, J.R. 2012. Behind uncertainties in projections of Australian tropical climate: Analysis of 19 CMIP3 models. J. Geophys. Res., 117 (D10103), doi:10.1029/2011JD017 365.

Nicholson, S.E., et al., 2003. Validation of TRMM and other rainfall estimates with a high-density gauge dataset for West Africa. Part I: Validation of GPCC rainfall product and pre-TRMM satellite and blended products. J. Appl. Meteorol., 42, 1337-54.

Pfahl, S. and Wernli, H. 2012. Quantifying the relevance of cyclones for precipitation extremes. J. Clim., 25, 6770-80.
Pitt, M. 2008. The Pitt Review - Lessons learned from the 2007 summer floods, Final Report. Environ. Agency, London.

Schaller, N., Mahlstein, I., Cermak, J. and Knutti, R. 2011. Analyzing precipitation projections: A comparison of different approaches to climate model evaluation. J. Geophys. Res., 116 (D10118), do:10.1029/2010JD014963

Simmonds, I., Keay, K. and Bye, J.A.T. 2011. Identification and climatology of Southern Hemisphere mobile fronts in a modern reanalysis. J. Clim., 25, 1945-62.

Stephens, G.L., et al. 2010. Dreary state of precipitation in global models. J. Geophys. Res., 115, doi:10.1029/2010JD014532.

Sun, Y., Solomon, S., Dai, A. and Portmann, R.W. 2006. How often does it rain? J. Clim., 19, 916-34.

Watterson, I.G. 2006. The intensity of precipitation during extratropical cyclones in global warming simulations: A link to cyclone intensity? Tellus, 58A, 82-97.

Wilcox, E.M. and Donner, L.J. 2007. The frequency of extreme rain events in satellite rain-rate estimates and an atmospheric general circulation model. J. Clim., 20, 53-69.

Williams, K.D. and Tselioudis, G. 2007. GCM intercomparison of global cloud regimes: present-day evaluation and climate change response. Clim. Dyn., 29, 231-50.

Wilson, D.R., Bushell, A.C., Kerr-Munslow, A.M., Price, J.D. and Morcrette, C.J. 2008. PC2: A prognostic cloud fraction and condensation scheme. I: Scheme description . Q. J. R. Meteorol. Soc., 134, 2093-107, doi: 10.1002/qj.333. 
204 Australian Meteorological and Oceanographic Journal 63:1 March 2013 